\title{
Characterization of the Transglycosylation Reaction of 4- $\alpha$ - Glucanotransferase (MalQ) and Its Role in Glycogen Breakdown in Escherichia coli
}

\author{
Dang Hai Dang Nguyen ${ }^{1 \dagger}$, Sung-Hoon Park ${ }^{2 \dagger}$, Phuong Lan Tran ${ }^{3}$, Jung-Wan Kim ${ }^{4}$, Quang Tri Le ${ }^{5}$, Winfried Boos ${ }^{6}$, \\ and Jong-Tae Park ${ }^{7 *}$ \\ ${ }^{1}$ Department of Foodservice Management and Nutrition, Sangmyung University, Seoul 03016, Republic of Korea \\ ${ }^{2}$ Research Institute of Food and Biotechnology, SPC Group, Seoul 08826, Republic of Korea \\ ${ }^{3}$ Department of Food Technology, An Giang University, Vietnam \\ ${ }^{4}$ Department of Biology, University of Incheon, Incheon 22012, Republic of Korea \\ ${ }^{5}$ Faculty of Food Science, Tien Giang University, My Tho, Vietnam \\ ${ }^{6}$ Department of Biology, University of Konstanz, Germany \\ ${ }^{7}$ Department of Food Science and Technology, Chungnam National University, Daejeon 34134, Republic of Korea
}

Received: November 28, 2018

Revised: January 16, 2019

Accepted: January 19, 2019

First published online January 29, 2019

*Corresponding author Phone: +82-42-821-6728; Fax: +82-42-821-8785;

E-mail: jtpark@cnu.ac.kr

${ }^{+}$These authors contributed equally to this work.

pISSN 1017-7825, eISSN 1738-8872

\section{Copyright(C) 2019 by}

The Korean Society for Microbiology and Biotechnology
We first confirmed the involvement of MalQ (4- $\alpha$-glucanotransferase) in Escherichia coli glycogen breakdown by both in vitro and in vivo assays. In vivo tests of the knock-out mutant, $\triangle m a l Q$, showed that glycogen slowly decreased after the stationary phase compared to the wild-type strain, indicating the involvement of MalQ in glycogen degradation. In vitro assays incubated glycogen-mimic substrate, branched cyclodextrin (maltotetraosyl- $\beta-C D$ : $G 4-\beta-C D$ ) and glycogen phosphorylase (GlgP)-limit dextrin with a set of variable combinations of $E$. coli enzymes, including GlgX (debranching enzyme), MalP (maltodextrin phosphorylase), GlgP and MalQ. In the absence of GlgP, the reaction of MalP, GlgX and MalQ on substrates produced glucose-1-P (glc-1-P) 3-fold faster than without MalQ. The results revealed that MalQ led to disproportionate G4 released from GlgP-limit dextrin to another acceptor, G4, which is phosphorylated by MalP. In contrast, in the absence of MalP, the reaction of GlgX, GlgP and MalQ resulted in a 1.6-fold increased production of glc-1-P than without MalQ. The result indicated that the G4-branch chains of GlgP-limit dextrin are released by GlgX hydrolysis, and then MalQ transfers the resultant G4 either to another branch chain or another G4 that can immediately be phosphorylated into glc-1-P by GlgP. Thus, we propose a model of two possible MalQ-involved pathways in glycogen degradation. The operon structure of MalP-defecting enterobacteria strongly supports the involvement of MalQ and GlgP as alternative pathways in glycogen degradation.

Keywords: Glycogen degradation, MalQ, Escherichia coli, 4- $\alpha$-glucanotransferase, transglycosylation

\section{Introduction}

As the most widespread polysaccharide in living cells, glycogen is present in all cells and tissues of animals, fungi, and bacteria. Many microorganisms accumulate glycogen as a carbon and energy reserve to cope with harsh environmental conditions. It is also known that Escherichia coli and Vibrio spp. accumulate glycogen in large quantities when grown under a shortage of nitrogen with an excess of carbon [1-7]. In contrast, cyanobacteria containing chlorophyll $a$ 
Table 1. Enzymes involved in glycogen breakdown from various bacterial strains.

\begin{tabular}{|c|c|c|c|c|c|c|c|c|}
\hline \multirow{2}{*}{ Microorganisms } & \multicolumn{2}{|c|}{ Transferring enzyme } & \multicolumn{3}{|c|}{ Debranching enzyme } & \multicolumn{2}{|c|}{ Phosphorylase } & \multirow{2}{*}{ Ref } \\
\hline & $\alpha$-GTase type & CGTase type & Glg $X^{*}$ type & Pul type & Specificity (DP) & MalP & $\mathrm{GlgP}$ & \\
\hline \multicolumn{9}{|l|}{ Enteropathogenic bacteria } \\
\hline E. coli & $\mathrm{O}$ & & $\mathrm{O}$ & & 4 & $\mathrm{O}$ & $\mathrm{O}$ & This study \\
\hline Salmonella & $\mathrm{O}$ & & $\mathrm{O}$ & & 4 & $\mathrm{O}$ & $\mathrm{O}$ & [29] \\
\hline Vibrio vulnificus & $\mathrm{O}$ & & $\mathrm{O}$ & & 4 & $\mathrm{O}$ & $\mathrm{O}$ & This study \\
\hline Aeromonas & $\mathrm{O}$ & & $\mathrm{O}$ & & - & $\mathrm{O}$ & $x$ & [20] \\
\hline \multicolumn{9}{|l|}{ Alteromonadales } \\
\hline Saccharophagus degradans & $\mathrm{O}$ & & $\mathrm{O}$ & & - & $x$ & $\mathrm{O}$ & [27] \\
\hline Alteromonas macleodii & $\mathrm{O}$ & & $\mathrm{O}$ & & - & $x$ & $\mathrm{O}$ & [27] \\
\hline \multicolumn{9}{|l|}{ Others } \\
\hline Bacillus subtilis & & & & $\mathrm{O}$ & $3-5$ & $x$ & $\mathrm{O}$ & [21] \\
\hline B. cereus & & $\mathrm{O}$ & & $\mathrm{O}$ & - & $x$ & $\mathrm{O}$ & [21] \\
\hline Sulfolobus solfataricus & & $\mathrm{O}$ & & $\mathrm{O}$ & $4-8$ & $x$ & $\mathrm{O}$ & [25] \\
\hline Nostoc punctiforme & $\mathrm{O}$ & & & $\mathrm{O}$ & $2-8$ & $x$ & $\mathrm{O}$ & [42] \\
\hline
\end{tabular}

*GlgX type was defined on the basis of the specificity of $E$. coli debranching enzyme. GlgX is not a typical isoamylase but shows high activity with phosphorylase-limit dextrin [17] and only very little activity with native glycogen.

-: not determined

are able to produce glycogen in the absence of carbon [8]. Several studies have suggested that bacteria need glycogen to provide energy for survival, colonization, and virulence [9-12]. However, the degradation pathway of glycogen in bacteria remains unknown, although it has been wellstudied in eukaryotes. In eukaryotes, the outer chains of glucose residues with DP (degree of polymerization) = 1113 are first attacked by glycogen phosphorylase, which sequentially removes glucose via the formation of glucose1-P (glc-1-P). The enzyme continues the phosphorolysis reaction until it reaches a location four glucose residues from the branch point, where its action stops, providing GlgP-limit dextrin for further degradation of the debranching enzyme. Then, the enzyme transfers three glucose residues of GlgP-limit dextrin to the neighboring glycogen-attached chain via the formation of branches of DP 7, which can be further shortened by GlgP, while the remaining glucosyl residue is hydrolyzed by the same enzyme. Therefore, the debranching enzymes in eukaryotes, such as animals and yeast, have been referred to as 'indirect' debranching enzymes in which the enzyme has both glucanotransferase and amylo-1,6-glucosidase activities [13]. In contrast, the bacterial debranching enzyme, known as a 'direct' debranching enzyme, catalyzes the hydrolysis of the $\alpha-1,6-$ glucosidic linkage of glycogen, releasing branch chains $(\mathrm{DP}=4)$ from glycogen, which was previously processed by GlgP. The debranching enzyme in E.coli, GlgX, which has a high substrate specificity for DP 4 branch, hydrolyzes the $\alpha-1,6$ branch to release maltotetraose (G4). The further degradation of maltodextrins, such as G4, is assisted by MalQ (amylomaltase), which is known as a transferase and is involved in the elongation of maltose to maltodextrin. The resulting maltodextrins with DP $>7$ are phosphorolyzed glc-1-P by MalP (maltodextrin phosphorylase). In E.coli, however, there are two phosphorylase isoenzymes, MalP and GlgP (glycogen phosphorylase; Table 1 and Fig. 1). These two enzymes have been characterized to some extent with respect to their substrate specificity and mechanism. Under the assumption that the formation of glc-1-P by either GlgP or MalP is an essential step for glycogen breakdown, an enzyme (MalQ) possessing transferase activity appears to be required for linking the GlgX-released G4 and phosphorolysis reaction.

However, few details are available regarding the metabolism of the short maltodextrin, G4, in relation to MalQ, MalP and GlgP, and even less has been investigated regarding the mechanism for the concurrent action of the complex enzyme system [7]. Thus, we investigated the role of MalQ in vivo and in vitro as the transferring enzyme in glycogen breakdown and proposed a possible novel pathway of glycogen breakdown in E. coli. 
Enterobacteriales (Escherichia coli)

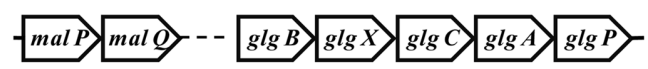

Pasteurellales

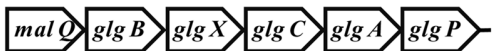

Vibrionales

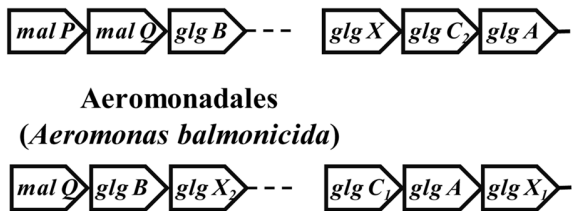

Alteromonadales

(Pseudoalteromonas, SM9912)

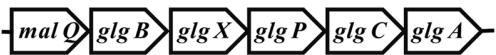

Saccharophagus degradaus 2-40

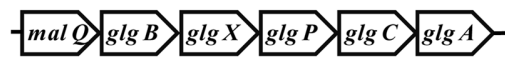

Fig. 1. Glycogen gene clusters in Escherichia coli and other bacteria.

Sources: E. coli [6], Pasteurellales, Vibrio anguillarum, Aeromonas balmonicida and Pseudoalteromonas, SM9912 [18], Saccharophagus degradans 2-40 [17]. In E. coli, malQ (encoding an amylomaltase) and malP (encoding a maltodextrin phosphorylase) are separated from a glycogen gene cluster that consists of $g l g B$ (encoding a branching enzyme), $g l g X$ (encoding a glycogen debranching enzyme), glgC (ADP-glucose pyrophosphorylase), glgA (glycogen synthase), and $g \lg P$ (glycogen phophorylase). In other bacteria, however, malQ is found in the same cluster as genes involved in glycogen metabolism. Genes and encoding proteins were experimentally analyzed or annotated by their encoding amino acid sequences.

\section{Materials and Methods}

\section{Chemicals}

Pure maltodextrin (purity $\geq 90 \%$ ) from DP 3 to 10 was purchased from CARBOEXPERT Inc. (Korea)

\section{Preparation of the MalQ Mutant of MC4100}

The MalQ deletion strain was constructed according to the method of Park JT et al. [14]. The strain was cultured in M63 minimal salts supplemented with a specific carbon source at $37^{\circ} \mathrm{C}$ with shaking. The cells were harvested at various stage of cell growth. The collection and quantification was carried out as described previously by Park et al. [14]. The harvested cells were washed twice with cold water, resuspended in $50 \mathrm{mM}$ sodium acetate ( $\mathrm{pH} 4.5)$ and boiled for $10 \mathrm{~min}$. The resuspension was then sonicated at room temperature. Glycogen in crude cell extract was collected by ethanol precipitation and centrifugation and air dried. The quantification of glycogen was calculated from the sum of peak areas in the HPAEC chromatogram and bovine glycogen standard curve.

\section{Expression and Purification of MalQ}

E. coli BL21 (DE3) was used as the host for the expression of plasmid pET29b_malQ encoding enzyme MalQ [14]. E. coli transformants were cultured in LB medium (1\% Bacto tryptone, $0.5 \%$ yeast extract, and $0.5 \% \mathrm{NaCl}$ ) containing kanamycin $(20 \mu \mathrm{g} / \mathrm{ml})$ at $37^{\circ} \mathrm{C}$ for $12 \mathrm{~h}$. Six-His-tagged MalQ was purified using an Ni-NTA column $(1 \times 4 \mathrm{~cm}$, Ni-NTA Superflow; Qiagen, Hilden, Germany). The eluted target protein was concentrated using an ultrafiltration kit (Millipore, USA) and dialyzed against $50 \mathrm{mM}$ Tris- $\mathrm{HCl}$ buffer ( $\mathrm{pH}$ 7.5). The purity of the enzyme was confirmed by sodium dodecyl sulfate-polyacrylamide gel electrophoresis (SDS-PAGE).

\section{Overexpression and Purification of Glycogen Phosphorylase (GlgP)}

The glgp gene was amplified by PCR from genomic DNA of E.coli K12, with the addition of restriction sites (underlined below) required for cloning. The primers were GlgP/Xbal (5'CGG AAA AAT CTA GAA CCC TTT GGC CCC GTT C-3') and GlgP/Ndel (5'-GAA ACG CCC ATA TGA ATG CTC CGT TTA CAT ATT C-3'). The PCR product was digested with Ndel and $\mathrm{Xbal}$, and ligated into identically cut pTKNd6xH. The resulting construct (pTKNd6xH_GlgP) was transformed into E. coli MC1061 and transformants were cultured on LB medium with kanamycin $\left(50 \mu \mathrm{g} \mathrm{ml}^{-1}\right)$. GlgP was purified by Ni-NTA chromatography, and enzyme activity on glycogen as the substrate was measured using high-performance anion exchange chromatography (HPAEC).

Expression and Purification of GlgX

A recombinant plasmid for expressing E. coli $\mathrm{GlgX}$ was constructed previously [15]. E. coli GlgX was expressed and purified following the method described by Song et al. [15]. After purification, E. coli $\mathrm{GlgX}$ was concentrated and dialyzed against $50 \mathrm{mM}$ Tris- $\mathrm{HCl}$ buffer ( $\mathrm{pH}$ 7.5). VV2_1226 gene encoding a glycogen debranching enzyme was amplified from $V$. vulnificus MO6-24/0 genomic DNA by PCR using forward (CAACCATAA CCATGGCAACATCGCTCGCTC: Nco I site underlined) and reverse (GAAAAAGTAAACTCGAGAACGGCCGCTGT: Xho I site underlined) primers. The amplified VV2_1226 gene was treated with Nco I and Xho I restriction enzymes and ligated with pET28a(+) (Novagen, USA) that was digested with the same restriction enzymes. The recombinant plasmid carrying VV2-1226 gene was designated as pET28a_VV1226. E. coli BL21(DE3) harboring pET28a_VV1226 was cultured in 1 L LB broth supplemented with kanamycin $(100 \mu \mathrm{g} / \mathrm{ml})$ at $37^{\circ} \mathrm{C}$. After $15 \mathrm{~h}$ cultivation, the cells were harvested by centrifugation $(10,000 \times g, 15 \mathrm{~min})$, then disrupted using sonication. Soluble protein fraction was obtained by removing cell debris using centrifugation $(15,000 \times g, 15 \mathrm{~min})$. $V$. vulnificus debranching enzyme was purified by Ni-NTA affinity chromatography $(1 \times 4 \mathrm{~cm}$, Ni-NTA Superflow; Qiagen). 


\section{Synthesis of G4- $\beta-C D$ [21]}

Five milliliters of maltosyl transferase (TmMT) from Thermatoga maritima were added to a solution of $5 \%(\mathrm{w} / \mathrm{v})$ maltosyl $\beta$ cyclodextrin (G2- $\beta$-CD: CARBOEXPERT Inc., Korea) and 10\% (w/v) soluble starch in Mcllvaine's buffer ( $\mathrm{pH}$ 6.5). The reaction proceeded at $70^{\circ} \mathrm{C}$ for three days. The solution was then heated to $100^{\circ} \mathrm{C}$ for $20 \mathrm{~min}$ to inactivate the enzyme and loaded onto a C18 Sep-Pak column (Waters, USA) to remove small oligosaccharides. Analysis was performed using high-performance liquid chromatography (HPLC).

\section{Analysis of Reaction Products}

The reaction was conducted at $37^{\circ} \mathrm{C}$ in $50 \mathrm{mM}$ sodium-phosphate buffer ( $\mathrm{pH}$ 6.5). GlgP-limit dextrin (1\%) or G4- $\beta$-CD (0.5\%) was mixed with various combinations of MalQ $(20 \mathrm{mU} / \mathrm{mg}$ substrate), GlgX (20 mU/mg substrate), GlgP (20 mM/mg substrate), and MalP (20 mM/mg substrate).

For the specificity determination of branch chain length each GlgX was incubated with $1.0 \mathrm{mM}$ branched $\beta$-CDs (DP 2-8), and at suitable time intervals an aliquot was boiled for $5 \mathrm{~min}$ to stop the reaction before being stored at $0^{\circ} \mathrm{C}$.

(i) Thin-layer chromatography (TLC) analysis. Silica gel K5F TLC plates (Whatman, Maidstone, UK) were activated for $1 \mathrm{~h}$ at $110^{\circ} \mathrm{C}$. Samples were spotted onto plates which were then placed in a TLC chamber containing $n$-butanol:ethanol:water (5:5:3 v/v/v). Chromatography was conducted at room temperature. Reducing sugars were detected using the naphtol-sulfuric acid $\left(\mathrm{H}_{2} \mathrm{SO}_{4}\right)$ method. Each plate was thoroughly dried and dipped into a methanol solution containing $3 \mathrm{~g} \quad \mathrm{~N}$-(1-naphthyl)-ethylenediamine and $50 \mathrm{ml}$ concentrated $\mathrm{H}_{2} \mathrm{SO}_{4}$ per liter. Each plate was dried and placed in an oven at $110^{\circ} \mathrm{C}$ for $10 \mathrm{~min}$. Purple-black spots appeared on a white background.

(ii) HPAEC. The reaction mixtures were boiled for $10 \mathrm{~min}$, centrifuged at $12,000 \times \mathrm{g}$ for $10 \mathrm{~min}$, and filtered using syringe filter (pore diameter $0.2 \mu \mathrm{m}$; Gelman Science, Ann Arbor, MI). Products were applied to a CarboPac PA-1 column $(0.4 \times 25 \mathrm{~cm}$; Dionex, Sunnyvale, CA, USA) and analyzed on a HPAEC platform fitted with a pulsed amperometric detector (ED40; Dionex). Sixty-microliter aliquots of sample were injected. Elution was achieved using an $\mathrm{NaOAc}$ gradient in $150 \mathrm{mM} \mathrm{NaOH}$ (increasing from 60 to $180 \mathrm{mM} \mathrm{NaOAc}$ over 0-10 min, from 180 to $240 \mathrm{mM}$ over $10-16 \mathrm{~min}$, from 240 to $300 \mathrm{mM}$ over $16-27 \mathrm{~min}$, from 300 to $360 \mathrm{mM}$ over $27-44 \mathrm{~min}$, and from 360 to $372 \mathrm{mM}$ over $44-55 \mathrm{~min})$. The flow rate was $1 \mathrm{ml} \cdot \mathrm{min}^{-1}$.

\section{Preparation of Phosphorylase (GlgP)-Limit Dextrin}

The purified GlgP (75 $\mu \mathrm{g} / \mathrm{g}$ glycogen) was added to $1 \%$ purified E. coli glycogen solution in $100 \mathrm{mM}$ phosphate buffer ( $\mathrm{pH}$ 7.0). The reaction was conducted in a dialysis tube with $100 \mathrm{mM}$ phosphate buffer at $30^{\circ} \mathrm{C}$. After a $24 \mathrm{~h}$ reaction, further $\mathrm{GlgP}$ ( $35 \mu \mathrm{g} / \mathrm{g}$ glycogen) was added to the same reaction mixture against the same buffer solution for $24 \mathrm{~h}$. The reaction was stopped by boiling for $10 \mathrm{~min}$ and centrifuged for $20 \mathrm{~min}$ at $12,000 \mathrm{rpm}$. The limit dextrin formed was dialyzed against distilled water and freeze-dried. The glycogen phosphorylase limit dextrin was found to have a high content of G4 (Fig. 2).
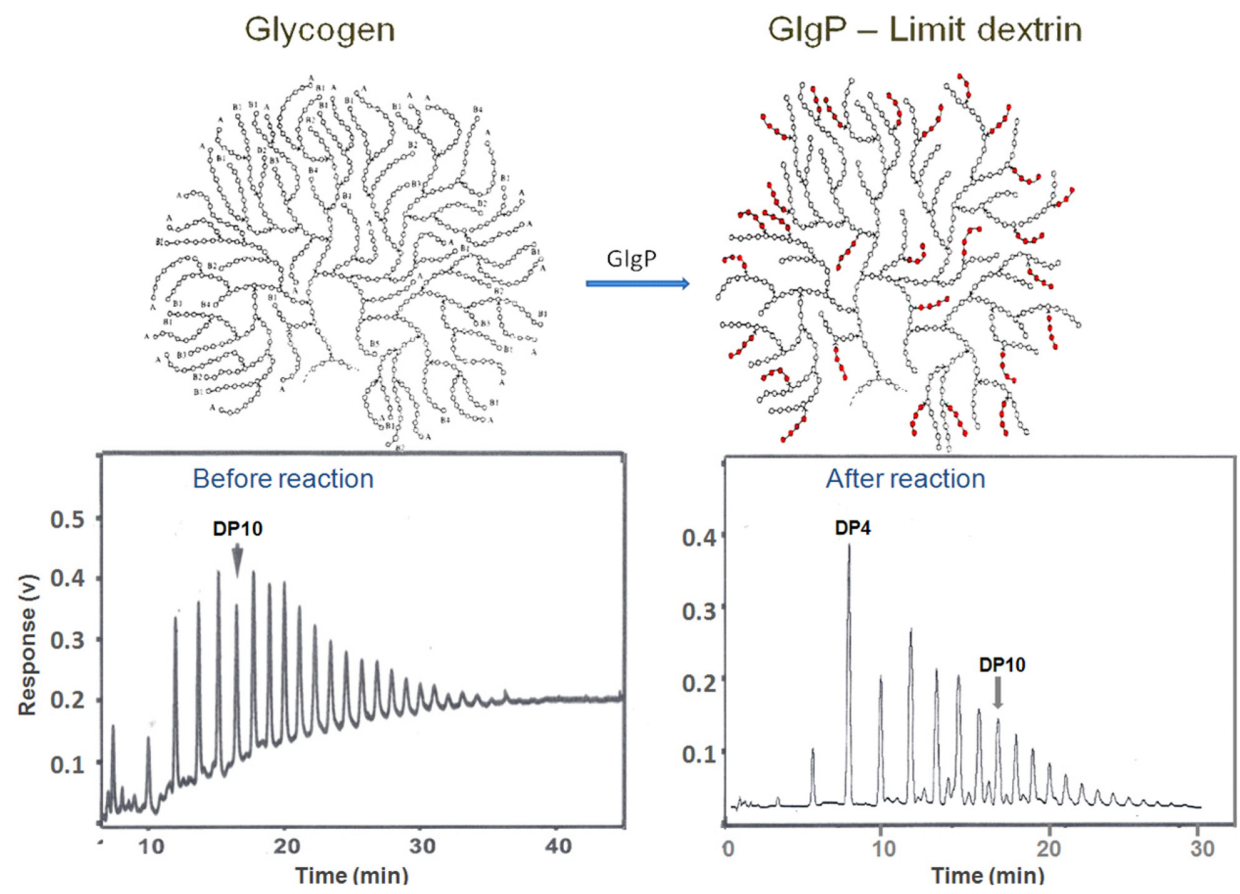

Fig. 2. Preparation of GlgP-limit dextrin from glycogen using E. coli glycogen phophorylase (a) and the analysis of the products by HPAEC (b). 
Table 2. Rates of glucose-1-P formation reactions by various combinations of glycogen breakdown enzymes.

\begin{tabular}{|c|c|c|c|c|c|c|c|c|}
\hline \multirow{2}{*}{ Substrate } & \multirow{2}{*}{$\mathrm{GlgP}$} & \multirow{2}{*}{ MalP } & \multirow{2}{*}{$\operatorname{Glg} X$} & \multirow{2}{*}{ MalQ } & \multicolumn{3}{|c|}{ Glucose-1-phosphate (mM) } & \multirow{2}{*}{$\begin{array}{l}\text { Rate constant } \\
\left(\mathrm{mM} \cdot \mathrm{min}^{-1} \times 10^{3}\right)\end{array}$} \\
\hline & & & & & $1 \mathrm{~h}$ & $3 \mathrm{~h}$ & $7 \mathrm{~h}$ & \\
\hline \multirow[t]{8}{*}{ GlgP-limit glycogen } & + & - & - & - & $0.002 \pm 0.001$ & $0.005 \pm 0.001$ & $0.012 \pm 0.002$ & $0.033 \pm 0.012$ \\
\hline & + & - & - & + & $0.012 \pm 0.001$ & $0.033 \pm 0.001$ & $0.081 \pm 0.003$ & $0.167 \pm 0.025$ \\
\hline & + & - & + & - & $0.126 \pm 0.012$ & $0.307 \pm 0.029$ & $0.591 \pm 0.075$ & $1.75 \pm 0.16$ \\
\hline & + & - & + & + & $0.253 \pm 0.028$ & $0.493 \pm 0.051$ & $0.889 \pm 0.076$ & $2.88 \pm 0.30$ \\
\hline & - & + & + & - & $0.013 \pm 0.002$ & $0.096 \pm 0.008$ & $0.266 \pm 0.020$ & $0.50 \pm 0.06$ \\
\hline & - & + & + & + & $0.082 \pm 0.009$ & $0.279 \pm 0.003$ & $0.563 \pm 0.048$ & $1.52 \pm 0.12$ \\
\hline & + & + & + & - & $0.151 \pm 0.011$ & $0.434 \pm 0.035$ & $0.919 \pm 0.075$ & $2.42 \pm 0.19$ \\
\hline & + & + & + & + & $0.472 \pm 0.033$ & $0.012 \pm 0.079$ & $1.32 \pm 0.13$ & $4.85 \pm 0.39$ \\
\hline \multicolumn{9}{|l|}{ G4- $\beta-C D$} \\
\hline w/o G4 & + & - & - & + & $0.010 \pm 0.001$ & $0.030 \pm 0.112$ & $0.050 \pm 0.003$ & $0.167 \pm 0.015$ \\
\hline w/ G4 & + & - & - & + & $0.100 \pm 0.012$ & $0.122 \pm 0.011$ & $0.150 \pm 0.013$ & $0.783 \pm 0.123$ \\
\hline
\end{tabular}

${ }^{a}$ Rate constants were calculated from the first $3 \mathrm{~h}$ reaction.

\section{Results}

\section{Roles of MalP and GlgP in Glycogen Breakdown}

To investigate the action of MalP and GlgP toward glc4, GlgP-limit dextrin was incubated with a mixture of MalP/ $\mathrm{Glg} X$ or GlgP/GlgX. Both of the mixtures of MalP or GlgP with $\mathrm{Glg} X$ produced significant amounts of glc-1-P in which the rate of glc-1-P formation was higher in the mixture of GlgP/GlgX $\left(1.75 \mathrm{mM} \mathrm{min}^{-1} \times 10^{-3}\right)$ than that of the MalP/GlgX $\left(0.5 \mathrm{mM} \mathrm{min}^{-1} \times 10^{-3}\right)$ (Table 2). The results revealed that G4 released from the substrate, GlgP-limit dextrin, by GlgX was more efficiently phosphorylated by GlgP than MalP, demonstrating that under test conditions in which G4 was rich in the outer layer of glgP-limit dextrin, $\mathrm{GlgP}$ may access the branches of $\mathrm{DP} \geq 4$ as a substrate, whereas MalP acts specifically toward the linear maltodextrins of DP $>7$ (Table 2).

Furthermore, the reaction mixture of GlgP/MalP/GlgX had a higher reaction rate $\left(2.417 \mathrm{mM} \mathrm{min}^{-1} \times 10^{-3}\right)$ than the reaction mixture without MalP $\left(1.75 \mathrm{mM} \mathrm{min}^{-1} \times 10^{-3}\right)$ or without $\operatorname{GlgP}\left(0.5 \mathrm{mM} \mathrm{min}^{-1} \times 10^{-3}\right)$, indicating that both GlgP and MalP significantly enhanced the rate of glc-1-P formation.

\section{MalQ and GlgX Share a High Specificity toward G4}

To determine the substrate specificity of MalQ and the relationship to $\mathrm{GlgX}$, various linear maltooligosaccharides of G3-G7 were incubated with MalQ, and the reaction products were analyzed by HPAEC. As shown in Fig. 3A, the analysis revealed various linear G3-G7 products, indicating that the substrates were disproportionately changed into shorter linear products or longer maltooligosaccharides by MalQ. In Fig. 3B, the decrease in substrate was plotted against reaction time, and the slope was determined as the initial velocity $\left(\mathrm{v}_{\mathrm{o}}\right)$ of MalQ for various substrates. The $\mathrm{v}_{\mathrm{o}}$ value of $0.19 \mu \mathrm{M} / \mathrm{h}$ for $\mathrm{G} 4$ was highest among those in the range of $0.1-0.11 \mu \mathrm{M} / \mathrm{h}$ for $\mathrm{G} 3$, G5, and G6. The results indicated that MalQ had its highest affinity toward G4, demonstrating that G4 is the best substrate for the MalQ reaction.

A previous kinetic study and the 3-D structure of GlgX have shown that the GlgX of E. coli predominantly debranches the branch chain of G4 [15, 16]. Both MalQ and GlgX had a high specificity toward G4 in the form of linear or branch chains of glycogen, respectively, implicating an efficient cooperation in the glycogen degradation process.

\section{MalQ Transfers Glucan Moieties from G4 Not Only to Other G4 Molecules but Also to the Branch Chain of Glycogen}

To understand the transfer action mechanism of MalQ, the mixture of G4- $\beta-C D$ and MalQ was reacted with and without G4. The TLC analysis clearly showed that the reaction in the presence of G4 produced a series of linear maltooligosaccharides with DP 2-7. Moreover, the reaction resulted in more $\beta$-CDs with various lengths of branch chains greater than $\mathrm{G} 4$, whereas reactions in the absence of glc4 produced fewer $\beta$-CDs with different branch lengths (Fig. 4). This suggests that G4 was transferred to other G4 molecules and/or to the branch chain, G4, of G4- $\beta-C D$ by the transglycosylation reaction of MalQ. To determine 
A

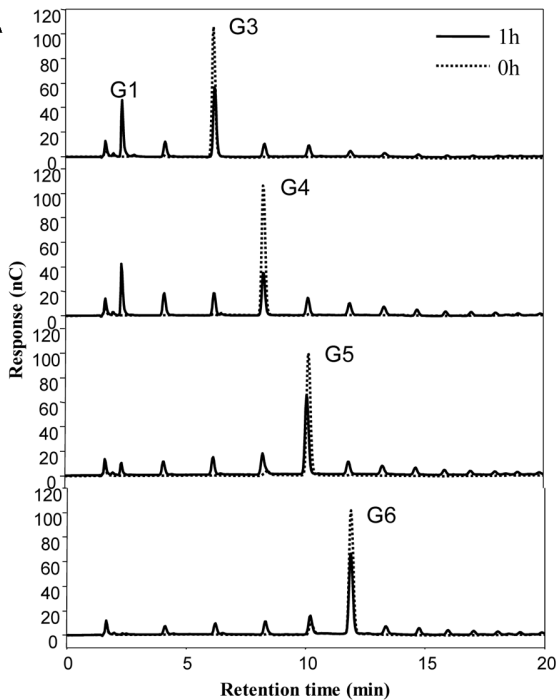

B

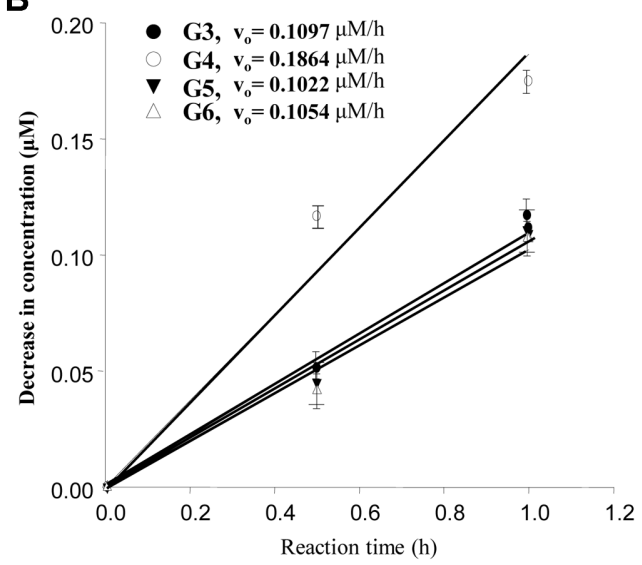

Fig. 3. Analyses of the reaction products (A) and the reaction rates (B) of MalQ with various maltooligosaccharides.

In a), the initial concentration $(7.8 \mu \mathrm{mol} / \mathrm{ml})$ of each maltodextrin was drawn in dotted lines. The reactions were conducted by adding MalQ $(20 \mathrm{mU})$ in $\mathrm{pH} 6.5$ sodium phosphate buffer $(50 \mathrm{mM})$ for $1 \mathrm{~h}$ at $37^{\circ} \mathrm{C}$, and the products were analyzed using HPAEC. Maltotriose (G3) to maltohexaose (G6) are indicated in the figure.

whether these products can be further phosphorylated by $\mathrm{GlgP}, \mathrm{GlgP}$ was added to the reaction mixture, and the rate of glc-1-P formation was determined. As shown in Table 2, more glc-1-P $\left(0.783 \mathrm{mM} \mathrm{min}^{-1} \times 10^{-3}\right)$ was produced in the presence of glc4 compared to that $\left(0.167 \mathrm{mM} \mathrm{min}^{-1} \times 10^{-3}\right)$ in the absence of glc4. These results suggest that the transglycosylation reaction can occur with G4 and/or glycogen branch chains in a similar manner.

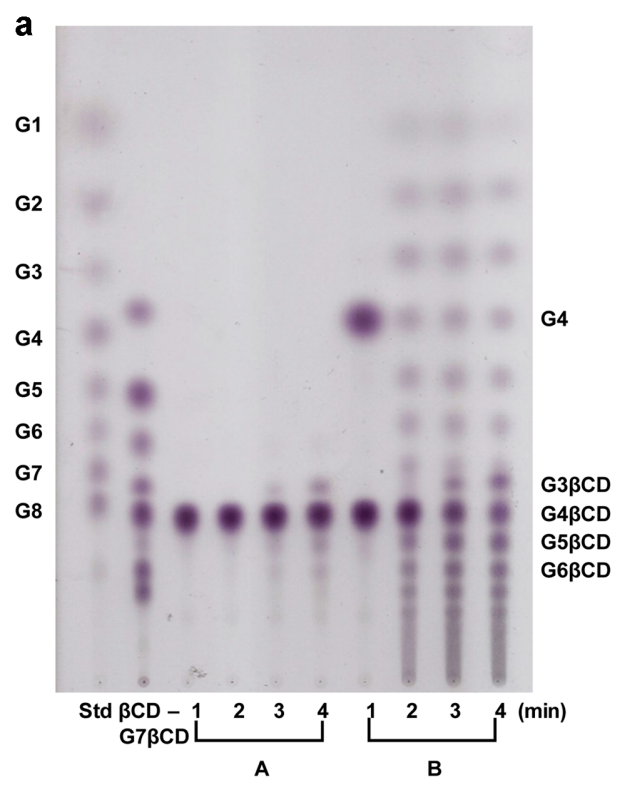

b

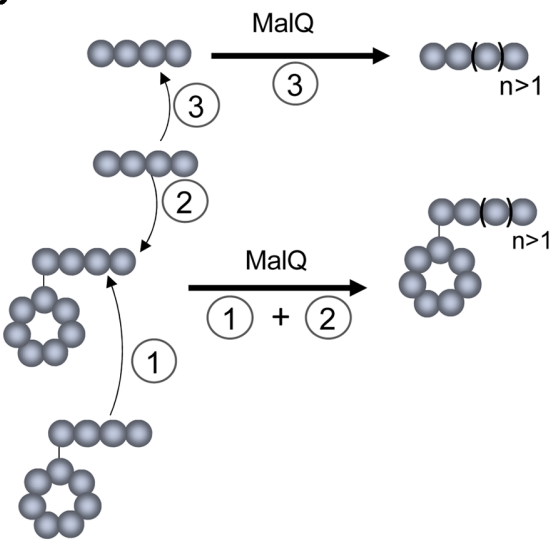

Fig. 4. Thin-layer chromatography (TLC) analysis (a) and schematic diagram (b) of the MalQ reaction with maltotetraosyl (G4)- $\beta$ $\mathrm{CD}$ in the presence (A) and absence (B) of G4.

The reactions were conducted in $\mathrm{pH} 6.5$ sodium phosphate buffer $(50 \mathrm{mM})$ at $37^{\circ} \mathrm{C}$. In the diagram (b), branched $\beta-\mathrm{CD}$ ( (1) ) or G4 ( (2) and (3) ) was used as a donor molecule in the transglycosylation reaction by MalQ. Maltodextrin standards (G1 to G8) are shown on the TLC analysis. 


\section{MalQ Enhances the Glycogen Breakdown Rate with the Cooperation of GlgX/GlgP/MalP}

To investigate the effect of MalQ, various combinations of enzyme mixtures were tested in the presence and absence of MalQ. When GlgP-limit dextrin was incubated with a mixture of GlgX and GlgP in the absence and presence of MalQ, the rate of formation of glc-1-P was $2.88 \mathrm{mM} \mathrm{min}^{-1} \times 10^{-3}$ in the presence of MalQ, whereas in the absence of MalQ, it was $1.75 \mathrm{mM} \mathrm{min}^{-1} \times 10^{-3}$ (Table 2). Furthermore, the mixture of $\mathrm{GlgP} / \mathrm{MalP} / \mathrm{GlgX}$ yielded the highest reaction rate $\left(4.85 \mathrm{mM} \mathrm{min}^{-1} \times 10^{-3}\right)$ in the presence of MalQ, which was considerably higher than in the absence of MalQ. All the pair combinations in the enzyme mixture significantly exhibited higher reaction rates in the presence of MalQ than in the absence of MalQ. The results clearly show that MalQ is involved in glycogen breakdown in E. coli. Based on these data, we suggest that MalQ is responsible for the transfer of the glucan moiety from GlgX-released G4 to other G4 molecules and/or branch chains in GlgP-limit dextrin that can then be further phosphorylated by GlgP and/or MalP.

In the absence of GlgP, such as in Vibrio spp., MalP likely controls glycogen degradation and vice versa in bacteria missing MalP, such as Alteromonadales [17]. Therefore, in most Vibrio spp. that lack GlgP (Table 1 and Figs. 1 and 5), G4 released from GlgP-limit glycogen (probably from the host cell) by $\mathrm{Glg} X$ is first elongated by MalQ and then degraded by MalP (Figs. 1 and 5). The results indicate that, as previously reported, the absence of GlgP in some gammaproteobacterial species (Fig. 1) could be compensated for by other enzymes that are capable of exerting the same effect, such as MalP [18]. Dauvillee et al. also postulated that the phosphorylase-limit dextrin is acted upon by GlgX to yield mainly G4, and the resulting G4 is thought to be

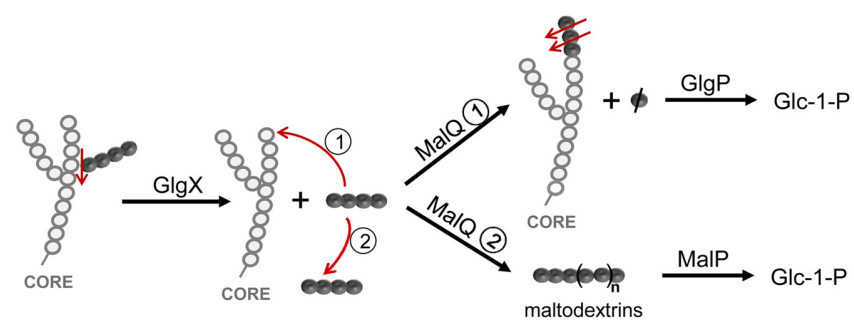

Fig. 5. Schematic diagram of glycogen breakdown in E. coli. When maltotetraose (G4) is released by $\mathrm{GlgX}$ from GlgP-limit glycogen, the G4 residue of free maltotetraose can be transferred to another glycogen external branch chain (2) or disproportionate within linear maltodextrins (1) by MalQ. The elongated products are efficiently degraded by $\mathrm{GlgP}$ or MalP.

disproportionately broken down by MalQ to maltodextrin, providing a substrate that is depolymerized into glc-1-P by MalP [16]. In contrast, E. coli and Salmonella, which possess both GlgP and MalP, have an efficient glycogen breakdown system that involves the cooperation of the two enzymes, GlgP and MalP (Fig. 5).

\section{MalQ Mutant Accumulates More Glycogen when Grown on Glucose}

To understand glycogen production and degradation during growth of E. coli in vivo, the glycogen content was determined at different culture times for the MalQ mutant. As shown in Fig. 6, the cell growth rates were similar in both MalQ mutant and wild-type MC 4100. In Fig. 6B, however, the glycogen content of the MalQ mutant was $0.18 \mathrm{mg} / \mathrm{ml}$ at $9 \mathrm{~h}$ of culture and $0.15 \mathrm{mg} / \mathrm{ml}$ at $10 \mathrm{~h}$ of culture, whereas those of the wild-type strain were $0.092 \mathrm{mg} / \mathrm{ml}$ and $0.06 \mathrm{mg} / \mathrm{ml}$, respectively. The results, that are well correspondent with previous study [14],
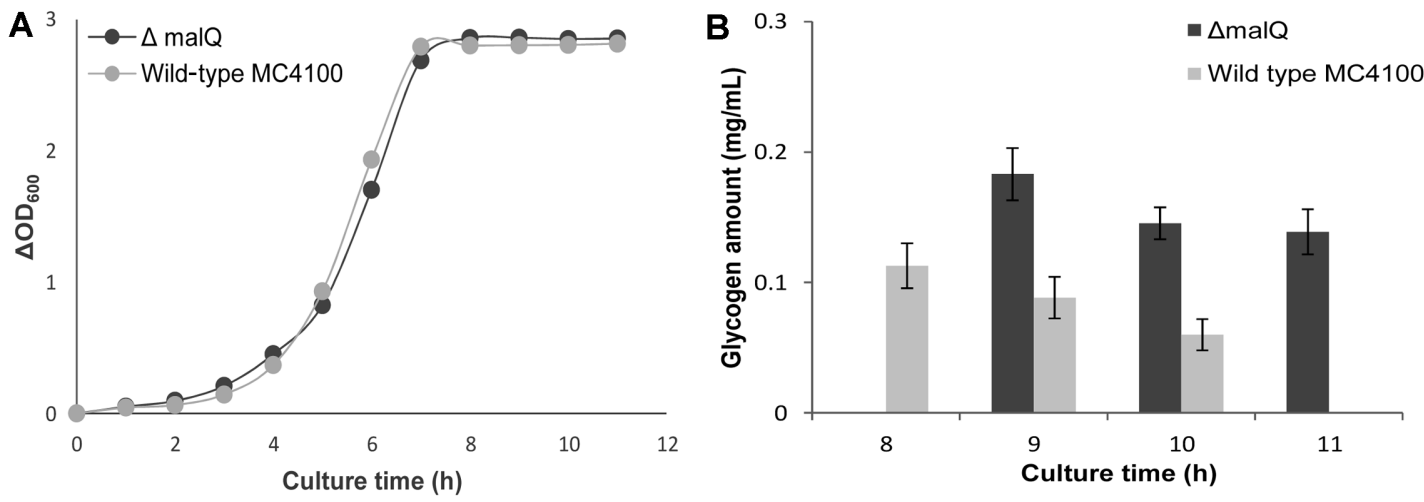

Fig. 6. Cell growth (A) and glycogen content (B) of wild-type and $\triangle m a l Q$ E. coli at various culture times. 
indicate that MalQ is involved in glycogen breakdown in the wild type, whereas glycogen breakdown was slowed in the absence of MalQ.

\section{Discussion}

\section{Efficient Cooperation of GlgX and MalQ in Glycogen Breakdown}

Previous studies have revealed that the GlgX-type debranching enzyme in enteropathogenic bacterial strains has a high specificity for the hydrolysis of chains consisting of three or four glucose residues, such as GlgP-limit dextrin $[15,16]$. From the 3D-structure of $\mathrm{GlgX}$, it is clear that a physical barrier exists in the substrate-binding groove, which is suitable only for G4 present in the outer layer of GlgP-limit dextrin [15]. Salmonella enterica hydrolyzes the $\alpha-1,6-$ glucosidic linkages in glycogen, which have been partially depolymerized by GlgP, indicating that the enzyme may have a high specificity toward G4 [19]. $V$. vulnificus also has a high branch chain preference for G4 (data not shown). The data above suggest that the debranching enzyme from enteropathogenic bacteria preferentially hydrolyze short branch chains, such as G4, and rarely attack the longer branch chains in glycogen (Table 1). As MalQ shares with GlgX the highest specific activity toward G4 (Fig. 3), GlgX and MalQ cooperatively trigger the continuous breakdown of GlgP-limit dextrin into glc-1-P.

\section{Substrate Specificities of GlgP and MalP in MalQ-Assisted Glycogen Breakdown}

In E. coli, the amino acid sequence of MalP has $45 \%$ similarity with that of GlgP. E. coli MalP prefers linear maltodextrins with DP 7, whereas its activity with glycogen is $90 \%$ lower. In contrast, the activity of E. coli $\mathrm{GlgP}$ with glycogen is four-fold higher than with maltodextrin. This indicates that GlgP and MalP differ in substrate specificity and regulation depending on the conditions in the cell $[6,20]$. The data in Table 2 showed that GlgP appears to have relatively high activity toward maltodextrins, including amylose, compared to MalP. Assuming that GlgP can phosphorylate G4 more efficiently than MalP, GlgP can be involved in the phosphorylation of both G4 and longer maltodextrins in the presence of MalQ. In addition, the $\mathrm{G} 4$ released from GlgP-limit glycogen by $\mathrm{Glg} X$ can be reincorporated into glycogen branch chains, generating glycogen molecules with longer branch chains, greater than DP 4, that can be further phosphorylated by $\mathrm{GlgP}$. This type of glucanotransferase transglycosylation is well-known in starch modification [21]. Several bacterial 4- $\alpha$-glucanotransferases, which show comparable substrate specificity to MalQ, catalyze the transfer of the glucan moiety from amylose to amylopectin branch chains, rearranging the branch chain lengths of amylopectin [22, 23]. The reincorporation of the glucan moiety G4 may possibly be beneficial to reduce the high osmotic pressure when G4 is released in excess into the cytosol.

\section{A Proposed Pathway for the Breakdown of Glycogen in E. coli}

An efficient model for the breakdown pathway in E. coli is proposed in Fig. 7. The outer glc4-branch chains of glycogen that were previously processed by $\mathrm{GlgP}$ are preferentially debranched by GlgX, releasing G4, which is immediately elongated by MalQ into longer maltodextrins of $>$ DP 5 or incorporated into other branch chains of glycogen and then further exposed to MalP /or GlgP phosphorolysis, respectively (Fig. 5). In some bacteria lacking MalP, such as Saccharophagus degradans 2-40 and Pseudoalteromonas, SM9912 (Alteromonadales), the degradation of glycogen may be controlled predominantly by GlgP [17]. In contrast, Vibrio spp. lacking GlgP may use the MalPcontrolled pathway. Of the enzymes involved in glycogen

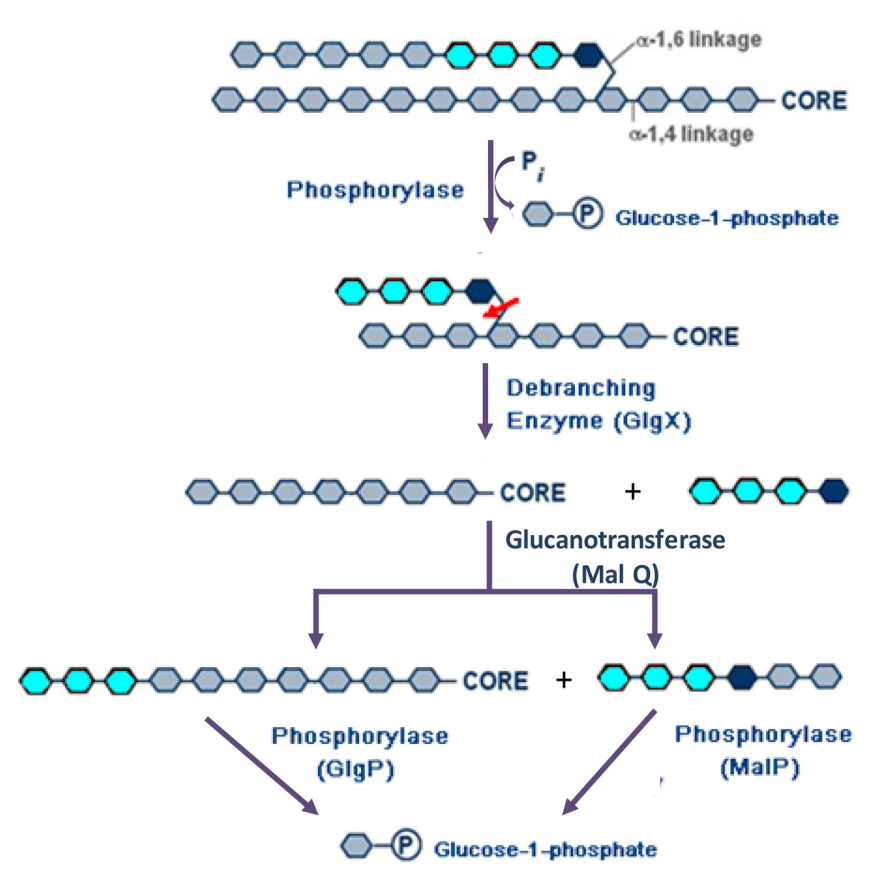

Fig. 7. A proposed model of the glycogen breakdown pathway in E. coli. MalQ catalyzes the transglycosylation of maltotetraose released from glycogen by GlgX, which is involved in glycogen degradation along with GlgP and/or MalP. 
breakdown, the GlgX-type debranching enzymes are conserved in enterobacteria, while the pullulanase-type debranching enzymes are present in Bacillus and others. As mentioned earlier, GlgX-type enzymes have a high specificity toward the DP 4 branch chain, but the pulluanase enzymes have specificity for a broad range of branch chain lengths (DP 3-7). Thus, enterobacteria possibly follow the proposed pathway of glycogen breakdown.

\section{Evolutionary Arrangements of Glycogen Genes, Including MalQ, GlgP and MalP}

Free-living bacteria have a complete set of glycogen enzymes. The minimal set includes one enzyme from each of the GT5, GT35, and GH13 families, which is probably sufficient for the management of simple glycogen metabolism [23]. Comparative genomic analyses of gammaproteobacterial $\mathrm{glg}$ genes have shown that the $g l g$ gene arrangement of these bacterial groups is remarkably conserved in the E. coli glycogen glgBXCAP operon, although an absence of GlgP or MalP is found in some gammaproteobacterial species [18; Fig. 1 and Table 1]. Thus, E. coli may share a common glycogen breakdown pathway with some phylogenetically-close gammaproteobacteria. In addition, a comparison of the enzymes involved in glycogen breakdown between Enterobacter (pathogens) and Bacillus indicated that intracellular MalQ is conserved in Eubacteria, while there are extracellular CGTases in Bacillus (Table 1), indicating that the glycogen degradation pathway can differ between E. coli and Bacillus [24].

A neighbor-joining tree indicated a high similarity (7077\%) among E. coli, Vibrio cholera, and Aeromonas species based on both proteins and genes [25, 26]. Furthermore, a phylogenetic analysis of the E. coli glycogen operon and Enterobacter revealed that $g l g$ BXCAP is highly conserved in Enterobacter and Pasteurellaes, indicating that it shares a common origin by horizontal gene transfer [18]. Vibrionales lacks $g l g \mathrm{P}$, whereas MalQ and MalP are located in close proximity in the same cluster [27]. Therefore, both MalQ and MalP are likely to function cooperatively in glycogen breakdown in Vibrio spp. Similarly, we suggest that MalQ is involved, along with MalP and/or GlgP, in the glycogen breakdown pathway in E. coli. This agrees with the fact that MalQ plays an important role in glycogen synthesis when grown on maltose-containing media [14].

On the other hand, the phylogenetic analysis of the $g l g$ genes reveals that MalQ is clustered in the glgBXCAP arrangement in $E$. coli and enteropathogenic species. In E. coli, however, the MalQ gene is physically separated from the glgBXCAP operon, whereas in Pasteurellales and Vibrioales, it is located in the same transcriptional operon as $g l g B X$ and $g l g B X C A P$, respectively [18]. Moreover, representative Aeromonadales, Alteromonadales species and Saccharophgus degradans conserve the arrangement of malQglgBX in the same cluster. A phylogenetic analysis, with a comparison of the glg genes cluster, suggests that MalQ would efficiently cooperate with $\mathrm{GlgX}$ and $\mathrm{GlgP}$, being located in the same cluster, to rapidly adapt the metabolism to environmental changes and biochemical needs [28-30].

Intriguingly, recent investigations of host-pathogen interactions have revealed that complex carbohydrates such as glycogen may serve as key carbon sources for infection of microbes, being involved in complex carbohydrate binding, transport, and metabolism, and contribute to microbial pathogenesis [13, 31-36]. Thus, the available data regarding microbial glycogen breakdown, including in the pathogens, may provide important insight into hostpathogen interactions.

\section{Acknowledgments}

This work was supported by a National Research Foundation of Korea (NRF) grant funded by the Korea government (MSIT) (No. 2015R1D1A1A01058005).

\section{Conflict of Interest}

The authors have no financial conflicts of interest to declare.

\section{References}

1. Carlson GM, Dienel GA, Colbran RJ. 2018. Novel insight into brain glycogen metabolism. J. Biol. Chem. 293: 7078-7088

2. Romeo T, Black J, Preiss J. 1990. Genetic regulation of glycogen biosynthesis in Escherichia coli: in vivo effects of the catabolite repression and stringent response systems in glg gene expression. Curr. Microbiol. 21: 131-137.

3. Boos W, Shuman H. 1998. Maltose/maltodextrin system of Escherichia coli: transport, metabolism and regulation. Microbiol. Mol. Biol Rev. 62: 204-229.

4. Ball SG, Morell MK. 2003. From bacterial glycogen to starch: understanding the biogenesis of the plant starch granule. Annu. Rev. Plant Biol. 54: 207-233.

5. Wilson WA, Roach PJ, Montero M, Fernandez EB, Munoz FJ, Eydallin G, et al. 2010. Regulation of glycogen metabolism in yeast and bacteria. FEMS Microbiol. Rev. 34: 952-985

6. Park KH. 2015. Roles of enzymes in glycogen metabolism and degradation in Escherichia coli. J. Appl. Glycosci. 62: 37-45. 
7. Jo HJ, Park SH, Jeong HG, Kim JW, Park JT. 2015. Vibrio vulnificus glycogen branching enzyme preferentially transfers very short chains: $\mathrm{N} 1$ domain determines the chain length transferred. FEBS Lett. 589: 1089-1094.

8. Yoo SH, Lee BH, Moon YY, Spalding MH, Jane JL. 2014. Glycogen synthase isoforms in Synechocystis sp. PCC6803: identification of different roles to produce glycogen by targeted mutagenesis. PLoS One 9: e91524.

9. Chang DE, Smalley DJ, Tucker DL, Leatham, MP, Norris WE, Stevenson SJ, et al. 2004. Carbon nutrition of Escherichia coli in the mouse intestine. Proc. Natl. Acad. Sci. USA 101: 7427-7432.

10. Bonafonte MA, Solano C, Sesma B, Alvarez M, Montuenga L, Garci-Ros D, et al. 2000. The relationship between glycogen synthesis, biofilm formation and virulence in Salmonela enteritidis. FEMS Microbiol. Lett. 191: 31-36.

11. Jones SA, Jorgensen M, Chowdhury FZ, Rodgers R, Hartline J, Leatham MP, et al. 2008. Glycogen and maltose utilization by Escherichia coli $\mathrm{O} 157: \mathrm{H} 7$ in the mouse intestine. Infect. Immun. 76: 2531-2540.

12. Bourassa L, Camilli A. 2009. Glycogen contributes to the environmental persistence and transmission of Vibrio cholera. Mol. Microbiol. 72: 124-138.

13. Cenci U, Nitschle F, Steup M, Minassian BA, Colleoni C Ball SG. 2014. Transition from glycogen to starch metabolism in archaeplastida. Cell 19: 18.

14. Park JT, Shim JH, Tran PL, Hong IH, Yong HU, Oktavina EF, et al. 2011. Role of maltose enzymes in glycogen synthesis by Escherichia coli. J. Bacteriol. 193: 2517-2526.

15. Song HN, Jung TY, Park JT, Park BC, Myung PK, Boos W, et al. 2010. Structural rationale for the short branched substrate specificity of the glycogen debranching enzyme GlgX. Proteins 78: 1847-1855.

16. Dauvillee D, Kinderf IS, Li Z, Hashemi BK, Samuel MS, Rampling L, et al. 2005. Role of the Escherichia coli glgX gene in glycogen metabolism. J. Bacteriol. 187: 1465-1473.

17. Hwang SM, Choi KH, Kim JU, Cha JH. 2013. Biochemical characterization of 4- $\alpha$-glucanotransferase from Saccharophagus degradans 2-40 and its potential role in glycogen degradation. FEMS Microbiol. Lett. 344: 145-151.

18. Almagro G, Viale AM, Montero M, Rahimpour M, Munoz FJ, Baroja-Fernandez E, et al. 2015. Comparative genomic and phylogenetic analyses of gammaproteobacterial $g l g$ genes traced the origin of the Escherichia coli glycogen glgBXCAP operon to the last common ancestor of the sister orders Enterobacteriales and Pasteurellales. PLoS One 10: e0115516.

19. Caspi R, Altman $T$, Billington $R$, Dreher $K$, Foerster $H$, Fulcher CA, et al. 2014. The MetaCyc database of metabolic pathways and enzymes and the BioCyc collection of pathway/ genome databases. Nucleic. Acids Res. 42: D459-D471.

20. Schinzel R, Nidetzky B. 1999. Bacterial $\alpha$-glucan phosphorylases. FEMS Microbiol Lett. 171: 73-79.

21. Nguyen DHD, Park JT, Shim JH, Tran PL, Oktavina EF, Nguyen TLH, et al. 2014. Reaction kinetics of substrate transglycosylation catalyzed by TreX of Sulfolobus solfataricus and effects on glycogen breakdown. J. Bacteriol. 196: 1941-1949.

22. Park SH, Na YR, Kim JW, Kang SD, Park KH. 2018. Properties and applications of starch modifying enzymes for use in the baking industry. Food Sci. Biotechnol. 27: 299-312.

23. Henrissat B, Deleury E, Coutinho PM. 2002. Glycogen metabolism loss: a common marker of parasitic behavior in bacteria? Trends Genet. 18: 437-440.

24. Shim JH, Park JT, Hong JS, Kim KW, Kim MJ, Auh JH et al. 2009. Role of maltogenic amylase and pullulanase in maltodextrin and glycogen metabolism of Bacillus subtilis 168. J. Bacteriol. 191: 4835-4844.

25. Yánez MA, Catalán V, Apráiz D, Figueras MJ, MartínezMurcia AJ. 2003. Phylogenetic analysis of the genus Aeromonas based on gyrB gene sequences. Int. J. System Evol. Microbiol. 53: 875-883.

26. Yoon YJ, Im KH, Koh YH, Kim SK, Kim JW. 2003. Genotyping of six pathogenic Vibrio species based on RFLP of 16S rDNAs for rapid identification. J. Microbiol. 41: 312-319.

27. Lim MS, Lee MH, Lee JH, Ju HM, Park NY, Jeong HS, et al. 2005. Identification and characterization of Vibrio vulnificus malPQ operon. J. Microbiol. Biotechnol. 15: 616-625.

28. Lawrence JG. 2002. Shared strategies in gene organization among prokaryotes and eukaryotes. Cell 110: 407-413.

29. Price MN, Huang KT, Arkin AP, Alm EJ. 2005. Operon formation is driven by co-regulation and not by horizontal gene transfer. Genome Res. 809: 15: 809-819.

30. Price MN, Arkin AP, Alm EJ. 2006. The life-cycle of operons. PLoS Genet. 2: e96.

31. Shelburne SA, Keith DB, Davenport MT, Beres SB, Carroll RK, Musser JM. 2009. Contribution of AmyA, an extracellular $\alpha-$ glucan degrading enzyme, to group A streptococcal hostpathogen interaction. Mol. Microbiol. 74: 159-174.

32. Shelburn SA, Sumby P, Sitkiewicz I, Okorafor N, Granville C, Patel $\mathrm{P}$ et al. 2006. Maltodextrin utilization plays a key role in the ability of group A Streptococcus to colonize the oropharynx. Infect. Immun. 74: 4605-4614.

33. McMeechan A, Lovell MA, Cogan TA, Marston KL, Humphrey TJ, Barrow PA. 2005. Glycogen production by different Salmonella enterica serotypes: contribution of functional $g \lg C$ to virulence, intestinal colonization and environmental survival. Microbiology 151: 3969-3977.

34. Abbott DW, Higgins MA, Hyrnuik S, Pluvinage B, Bueren ALvan, Boraston AB. 2010. The molecular basis of glycogen breakdown and transport in Streptococcus pneumoniae. Mol. Microbiol. 77: 183-199.

35. Alteri CJ, Smith SN, Mobley LT. 2009. Fitness of Escherichia coli during urinary tract infection requires gluconeogenesis and the TCA cycle. PLoS Pathog. 5: e1000448.

36. Lu C, Lei L, Peng B, Tang L, Ding H, Gong S, Li Z, et al. 2013. Chlamydia trachomatis GlgA is secreted into host cell cytoplasm. PLoS One 8: e68764. 